\title{
Determinants of Directional Specificity in the Regeneration of Lamprey Spinal Axons
}

\author{
Scott A. Mackler, Hsiang-Shu Yin, ${ }^{1}$ and Michael E. Selzer \\ Departments of Anatomy and Neurology, University of Pennsylvania School of Medicine, \\ Philadelphia, Pennsylvania 19104
}

The projection patterns of regenerating spinal axons in the larval sea lamprey (Petromyzon marinus) were determined by intracellular injection of HRP. Four hundred and eighty-six of 562 stained axons and axon-like neurites (87\%) arising from Muller and Mauthner axons, giant interneurons, and dorsal cells terminated in an orientation similar to that of their counterpart control cells. Therefore, lamprey spinal axons regenerate selectively along their normal projection paths.

During the first 4 weeks of recovery, i.e., before any had regenerated beyond the transection site, 91 of 114 axons and long neurites $(80 \%)$ projected in the proper direction. Thus, the correctness of the final projection patterns did not result from selective retraction of randomly directed long neurites. When the cords were doubly transected $1 \mathrm{~cm}$ apart, orientation of regenerating neurites remained normal both within the $1 \mathrm{~cm}$ island and in the adjacent spinal cord. This suggests that the directional specificity of axonal regeneration was determined neither by the location of the scar nor by the availability of channels formed by the degenerating fibers. Finally, removing $1 \mathrm{~cm}$ of spinal cord eliminated potential synaptic targets for regenerating axons on either side of the lesion, but did not affect the direction of axonal growth.

These findings are consistent with the hypothesis that the regeneration of lamprey spinal axons is guided by local chemical cues that persist long after the pathways are formed early in development.

Studies in developing vertebrate nervous systems have emphasized the importance of local environmental cues in the formation of precise pathways for motor neurons (Lance-Jones and Landmesser, 1981; Lewis et al., 1981; Tosney and Landmesser, 1984), retinal ganglion cells (Silver and Sidman, 1980), and Mauthner neurons (Hibbard, 1965; Jacobson, 1976; Stefanelli, 1951). Since the potential for functional recovery following CNS injury may ultimately depend on the precision of neuronal reconnections, it is of interest to know if these axonal guidance factors persist after axons have reached their targets. One approach to this question is to determine whether, in animals capable of successful CNS regeneration, fibers of axotomized neurons grow selectively along their normal paths.

Sea lamprey ammocoetes (larvae) 4-5 years old recover motor and sensory function following complete spinal cord transection (Ilibbard, 1963; Rovainen, 1976; Selzer, 1978). This behavioral recovery is accompanied by short distances of axonal regener-

\footnotetext{
Received Sept. 25, 1985; revised Nov. 25, 1985; accepted Nov. 26, 1985.

This work was supported by NIH Grants R01-NS14837 and T35-GM-07170 and by a grant from the American Paralysis Association.

Correspondence should be addressed to Michael E. Selzer, M.D., Ph.D., Department of Neurology, Hospital of the University of Pennsylvania, Philadelphia PA 19104.

' Present address: Department of Pharmacological and Physiological Sciences, University of Chicago, 947 East 58th Street, Chicago, IL 60637.

Copyright (C) 1986 Society for Neuroscience $0270-6474 / 86 / 061814-08 \$ 02.00 / 0$
}

ation (Rovainen, 1976; Selzer, 1978; Wood and Cohen, 1981; Yin and Selzer, 1983), and the regenerated fibers form functional synaptic connections with neurons on the opposite side of the lesion (Mackler and Selzer, 1985a). A preliminary study reported that, after axotomy, neurons in this preparation send out neurites selectively along their normal trajectories (Yin et al., 1984a). The directional specificity of regeneration is now confirmed with findings collected from over 500 axons of 3 classes of central neurons labeled by intracellular injection of HRP. This specificity could result if many regenerating neurites first grew in random directions and if those not projecting properly subsequently retracted. Alternatively, individual fibers could be subject to influences that guide their growth. In order to distinguish between these two hypotheses, the present study included observations on the orientations of regenerating fibers during the first 4 weeks post-transection. In this period, cut axons die back for $2 \mathrm{~mm}$ or more and then begin to regrow, but do not yet proceed beyond the scar. The direction of axonal growth is shown not to be a result of selective retraction of initially misdirected long neurites. Neither is it determined by a tropic effect of the scar or distant synaptic targets, nor by mechanical routing in pathways formed by degenerating fibers. More likely, regenerating neurites follow chemical cues in their local environment. Thus, the factors involved in initial axon guidance during development are maintained for many years after the axon tracts have been formed.

\section{Materials and Methods}

\section{Surgery}

Lamprey larvae (Petromyzon marinus) 8-14 cm in length (4-5 years old) were anesthetized in $0.1 \%$ Tricaine methanesulfonate and the spinal cord exposed via a dorsal incision through the overlying skin and muscle. The first experimental group ( 75 animals) received a single complete transection at either the level of the last gill slit or the cloaca. Double simultaneous transections $8-10 \mathrm{~mm}$ apart, also at the level of the last gill slit or the cloaca, were performed on a second group (23 animals). In the final group ( 5 animals), an attempt was made to reverse an 8-10 mm segment of spinal cord along the rostral-caudal axis at the level of the cloaca. The animals remained on ice for $1-2 \mathrm{hr}$ to facilitate clot formation and were returned to freshwater tanks for various recovery times.

\section{Intracellular dye injection}

Recovered and unoperated control animals were anesthesized and ventrally eviscerated. The spinal cord and notochord were removed and placed in a recording chamber containing Ringer's composed as follows (in $\mathrm{mM}$ ): $111 \mathrm{NaCl}, 2.1 \mathrm{KCl}, 2.6 \mathrm{CaCl}_{2}, 1.8 \mathrm{MgCl}_{2}, 10$ Tris maleate, and 4 glucose, $\mathrm{pH} 7.4$, at $10^{\circ} \mathrm{C}$. Microelectrodes were backfilled the night before with 4-8\% HRP in $0.2 \mathrm{M} \mathrm{K}$ acetate and $0.1 \mathrm{M}$ Tris, $\mathrm{pH} 7.4$. Those with resistances of 40-100 M $\Omega$ were selected. Spinal neurons and giant axons were transilluminated and impaled under stereomicroscopic vision. HRP was iontophoretically injected with 5-25 nA pulses of 200 msec duration at $3.3 \mathrm{~Hz}$ for $5-25 \mathrm{~min}$. At the conclusion of an experiment, the spinal cord was placed in fresh Ringer's and kept overnight at $4^{\circ} \mathrm{C}$. 

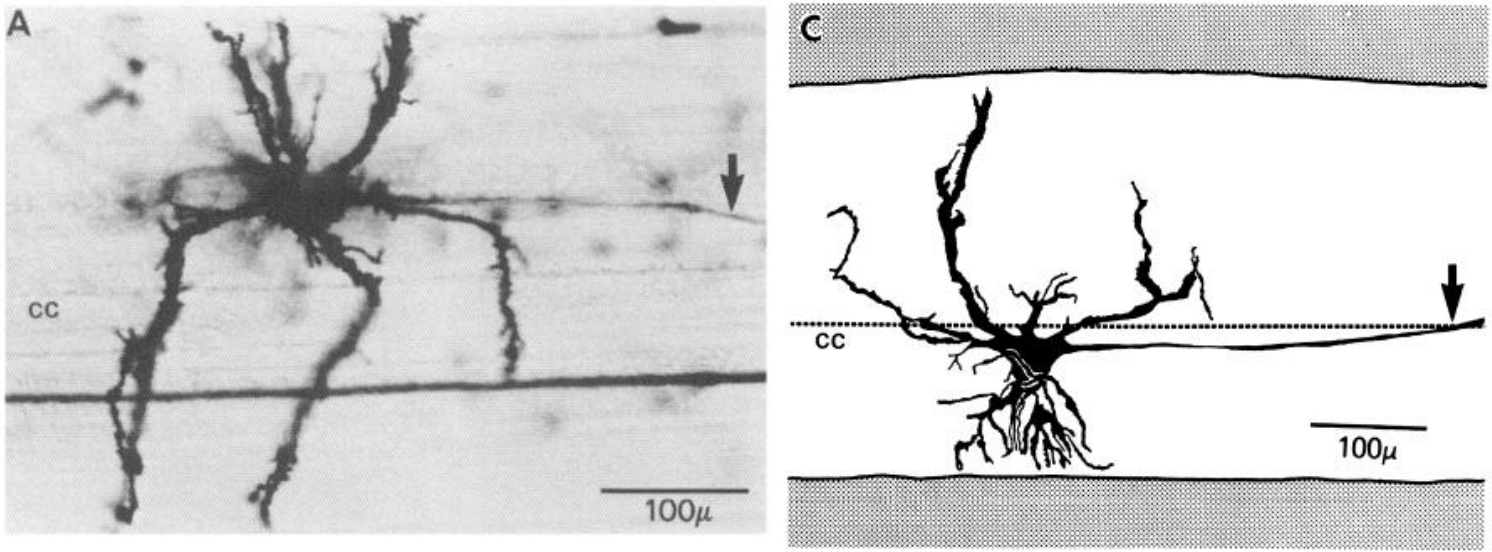

B
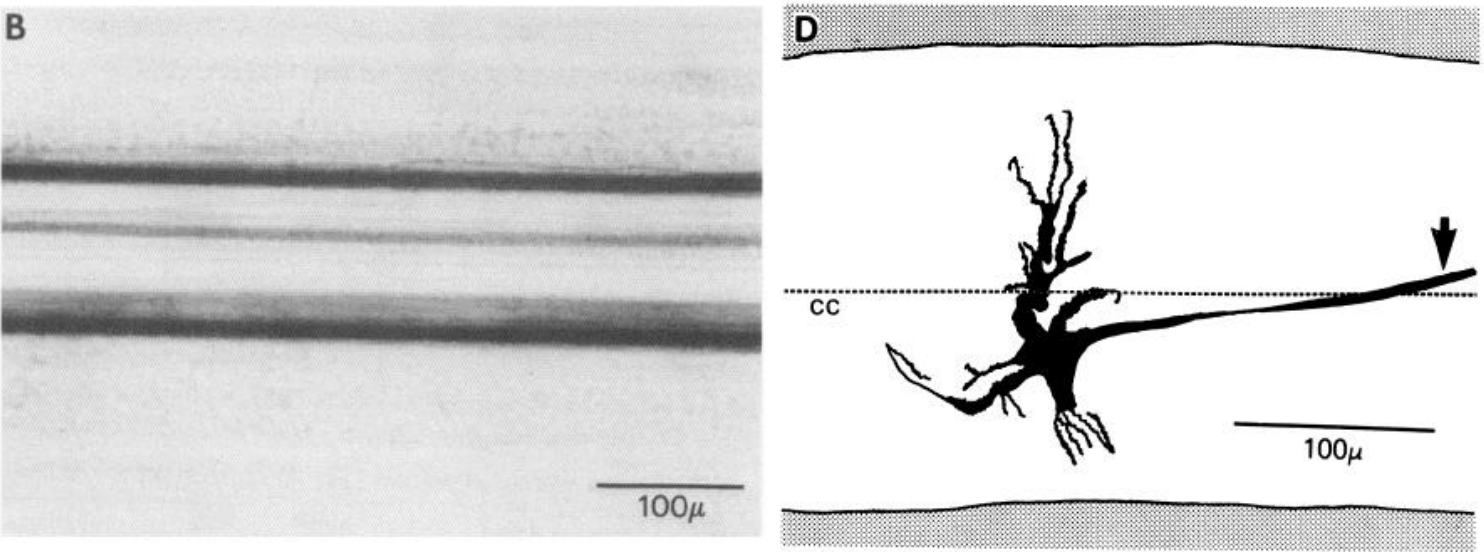

Figure 1. HRP-injected cells and axons from unoperated control spinal cords, as seen in whole-mount. Rostral is right in these and all subsequent micrographs and camera lucida drawings. $A$, Micrograph of control GI. A single axon (arrow) originates from the anteromedial surface of the soma and crosses to the contralateral side of the spinal cord (rostral to the border of the frame). $B$, Micrograph of 4 RAs, which remain unbranched and smooth. The bottom two partly overlap. $C, D$, Camera lucida drawings of GIs from 2 other control animals, both also with single decussating axons that arise anteromedially (arrows). $c c$, Central canal.

\section{HRP histochemistry}

Approximately one-half of the spinal cords were fixed in $2 \%$ glutaraldehyde for $2 \mathrm{hr}$ and processed for HRP reaction product in $0.1 \%$ diaminobenzidine and $1 \% \mathrm{H}_{2} \mathrm{O}_{2}$. The other cords were incubated in $0.1 \%$ $\mathrm{H}_{2} \mathrm{O}_{2}$ and the Hanker-Yates reagent at $10^{\circ} \mathrm{C}$ for 15 min (Hanker et al., 1977) and fixed in glutaraldehyde for $2 \mathrm{hr}$. All of the spinal cords were then dehydrated in serial ethanols, cleared in cedarwood oil, and mounted whole on glass slides, as previously described (Selzer, 1979). Both procedures yielded similar results, but the Hanker-Yates reagent was eventually preferred because it did not stain red blood cells located in the overlying membranes as darkly as did diaminobenzidine.

\section{Light-microscopic analysis}

HRP-stained neurons and giant axons were analyzed for the following: (1) the number of axons or long neurites (longer than $400 \mu \mathrm{M}$ ) per cell; (2) the final orientation of these fibers (rostral vs caudal, ipsilateral vs contralateral to the cell body or parent axon); (3) morphology of the tip; (4) the distance of the tip from the center of the scar; and (5) the number of primary $\left(1^{\circ}\right)$ and secondary $\left(2^{\circ}\right)$ dendrites. Primary dendrites were defined as those (regardless of caliber) that arose from the cell body. Secondary dendrites were those that were formed by the branching of $1^{\circ}$ dendrites. Small twigs emerging from a $1^{\circ}$ dendrite were defined as $2^{\circ}$ dendrites. However, if the main trunk did not change its direction, it was still called a $1^{\circ}$ dendrite, so that other branches emanating from it distally were still included as $2^{\circ}$ dendrites. The orientation parameters chosen for analysis were those that can be most reliably analyzed in the whole-mount. We did not attempt to specify individual fiber tracts, even though these could often be guessed at by focusing up and down on the whole-mount.

\section{Results}

\section{Normal axonal projections}

The normal projection patterns of axons in the larval lamprey spinal cord were first established. Giant interneurons (GIs), dorsal cells (DCs), and the giant reticulospinal axons (RAs) of Muller and Mauthner neurons were chosen for impalement. GIs are caudally positioned second-order sensory neurons which, in adult lampreys, send an axon contralaterally as far as the hindbrain, forming en passant synaptic connections along their course (Rovainen, 1967b). In 15 larval lamprey GIs, a single axon invariably arose from the anteromedial surface of the soma and decussated (Fig. 1). None of these axons changed its contralateral position (average distance of staining $=5002 \pm 4019$ SD; omission of 1 cell, whose axon stained for $18,000 \mu \mathrm{m}$, would yield mean distances of $4017 \pm 1306 \mu \mathrm{m})$. DCs are intramedullary primary sensory neurons that, in adult lampreys, also send single axons rostrally into the brain stem (Martin and Bowsher, 1977). In larvae, all axons of 17 control DCs remained ipsilateral to the cell body (stained for $2490 \pm 994 \mu \mathrm{m}$ ). RAs project caudally nearly to the distal end of the spinal cord and, in adult animals, do not decussate after entering the spinal cord (Rovainen, 1967a). In 28 control RAs of larvae (average distance of staining = $6394 \pm 1910 \mu \mathrm{m}$ ), no fibers branched or crossed to the opposite side of the spinal cord (Fig. $1 B$ ). GIs, DCs, and RAs each characteristically sent a single axon, which did not branch or change its position in the spinal cord for the distance it was followed. 

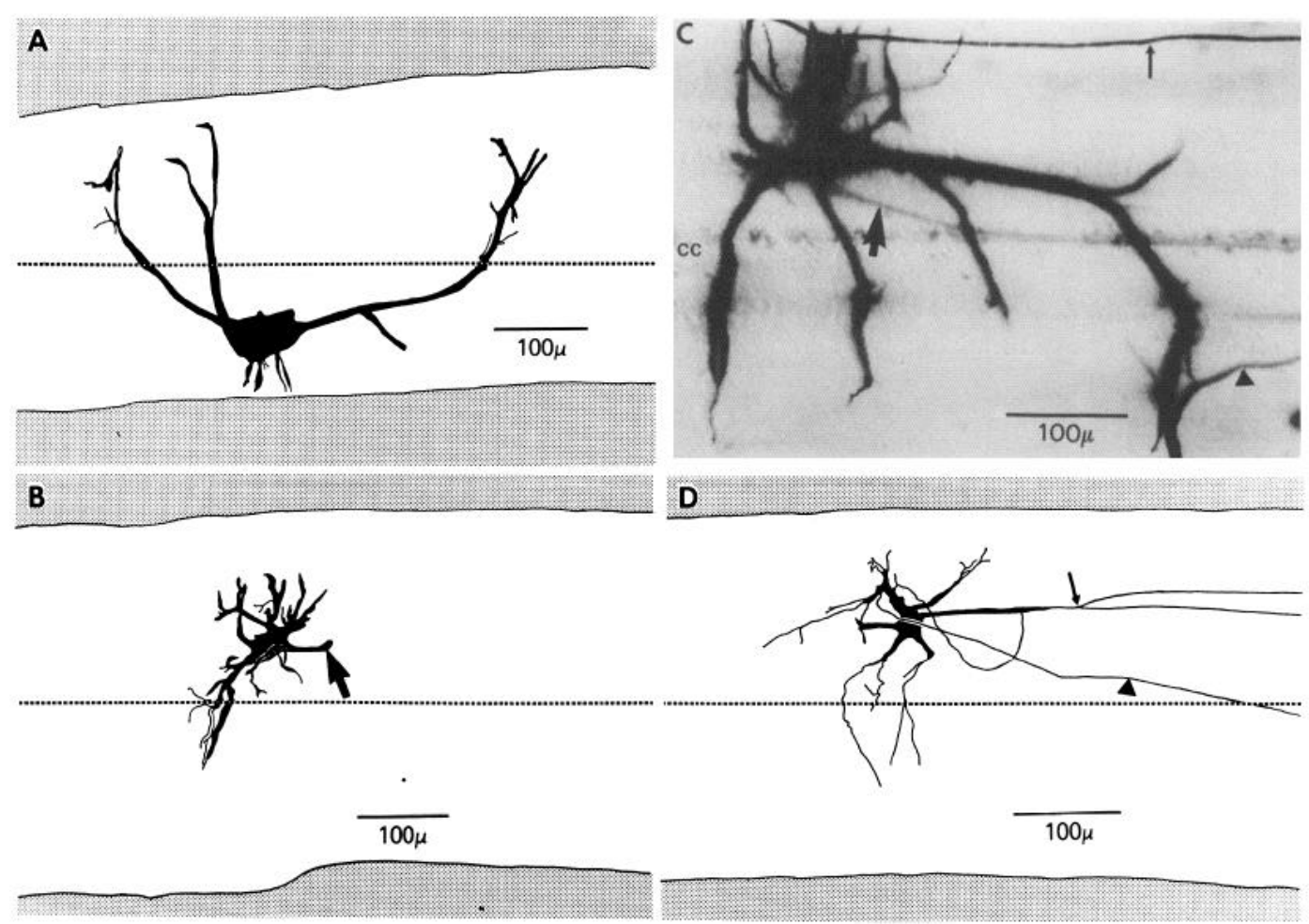

Figure 2. Axonal dieback and neurite outgrowth in axotomized GIs. $A, B$, GIs at 97 and $17 \mathrm{~d}$, respectively, following spinal cord transection. No axons or long axon-like neurites are apparent. In $B$ a large stump (arrow) arising anteromedially may represent the original axon, which has died back. $C, D$, GIs at 64 and $17 \mathrm{~d}$, respectively, with initially misoriented neurites. In $C$, the 2 neurites loop to project rostrally (small arrow and arrowhead). A third fiber, though originating slightly more posteriorly than normal, may be the original axon (arrow). The final projections of this cell are shown in Figure $6 A$. In $D$, one neurite grows from the dendritic tree and projects contralaterally and rostralward (arrowhead). Another neurite arises anterolaterally from the soma and bifurcates (small arrow). cc, Central canal.

\section{Projections of axotomized neurons in long-term survivors (more than 6 weeks after single transection)}

Thirty-eight GIs studied for more than $45 \mathrm{~d}$ post-axotomy gave rise to 74 axons and long neurites, of which $53(72 \%)$ projected correctly, rostral and contralateral to the cell body (Table 1). In 4 other cells there was no axon present, suggesting that complete dieback of the original axon had occurred (Fig. $2 A$ ). In 6 GIs 8 neurites grew from anomalous soma-dendritic locations and therefore were not directed properly at their origin (Fig. 2C). Seven of these initially misoriented neurites $(88 \%)$ crossed the midline, turned rostralward, and thus attained a correct orientation.

The majority of axons and neurites from RAs (91\%) and DCs ( $92 \%$ ) was also oriented similarly to those of control cells (Tables
2 and 3 ). In order to rule out the possibility that these results simply reflected retraction of axons without subsequent outgrowth, a subset of neurites was identified that had either branched or grown beyond the scar. These fibers must have undergone additional regrowth after retraction. One hundred and forty-nine of 162 such RAs (92\%) and 9 of 12 such DC axons (75\%) projected correctly (Fig. 3). Of these axons and neurites, 86 of 92 RAs $(94 \%)$ and 7 of 8 DCs $(88 \%)$ extended beyond the scar in proper pathways. This indicates that, even after growing through the disorganized scar tissue (Wood and Cohen, 1981), the majority of regenerating axons reorient themselves correctly.

Thus, for all 3 types of spinal axons examined in the time period necessary for the return of normal appearing behavior, directional specificity was a consistent finding.

\section{Table 1. Giant interneuron projection patterns}

\begin{tabular}{|c|c|c|c|c|c|}
\hline Experiment & $\begin{array}{l}\text { No. of } \\
\text { cells }\end{array}$ & $\begin{array}{l}\text { Correct projections } \\
\text { of total no. of axons } \\
\text { or neurites }(\%)^{a}\end{array}$ & $\begin{array}{l}\text { No. of cells } \\
\text { with initially } \\
\text { misoriented } \\
\text { neurites }^{b}\end{array}$ & $\begin{array}{l}\text { Correct projections } \\
\text { of total no. of } \\
\text { initially misoriented } \\
\text { neurites }(\%)\end{array}$ & $\begin{array}{l}\text { No. of cells } \\
\text { with at least } \\
\text { one correct } \\
\text { projection }(\%)^{a}\end{array}$ \\
\hline Single transection recovery $<30 \mathrm{~d}$ & 33 & $38 / 55 \quad(69)$ & 11 & $11 / 14(79)$ & $33 / 33(100)$ \\
\hline Island of double transection & 10 & $10 / 12(83)$ & 3 & $3 / 4 \quad(75)$ & $9 / 10(90)$ \\
\hline Caudal to missing spinal cord segment & 5 & $5 / 5 \quad(100)$ & 2 & $2 / 2 \quad(100)$ & $5 / 5 \quad(100)$ \\
\hline
\end{tabular}

\footnotetext{
${ }^{a}$ Correct projection defined as rostral and contralateral to cell body.
}

${ }^{b}$ Initially misoriented neurites are long axon-like processes that originate at points distant from the normal axon hillock. Thus they are new fibers which at their origins project anomalously. In order to assume a correct final projection, they must change the direction of their growth. 

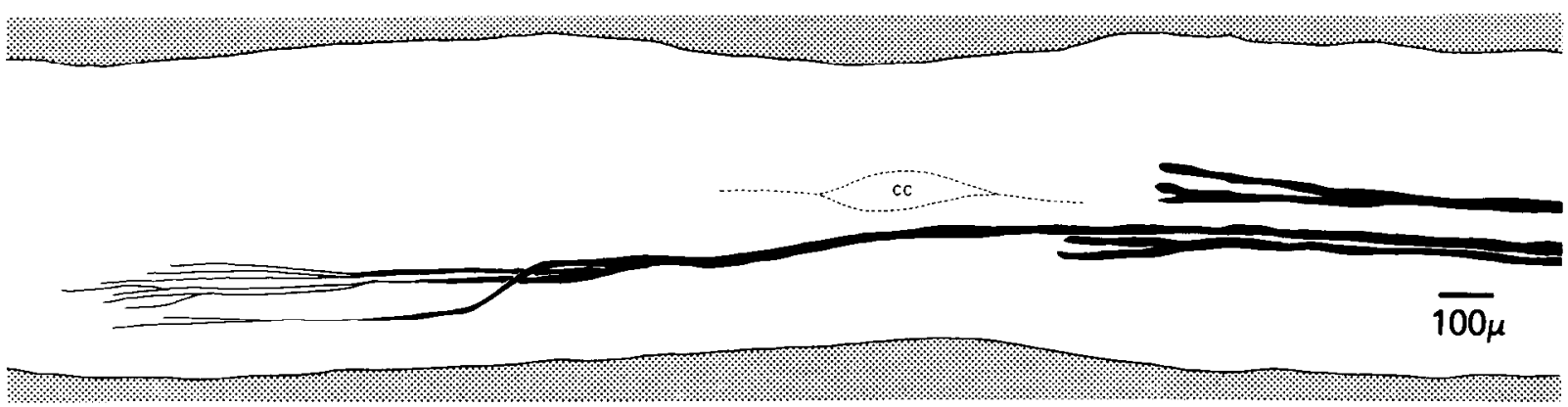

Figure 3. Directionally specific regeneration of RA branches. Three RAs with multiple branches are shown from an animal $58 \mathrm{~d}$ after single transection. All of the branches represent new growth and project correctly (ipsilaterally and caudalward). This includes an exceptional RA that gives rise to 9 branches caudal to the scar. The narrowing of the spinal cord and widening of the central canal (cc) identify the location of the healed scar.

\section{Early projection patterns-first 4 weeks} after a single transection

The appearance of directional specificity in axonal regeneration could be achieved even if neurites grew in random directions, as long as the incorrectly oriented ones were subsequently removed. In order to test for this possibility, we examined the projection patterns of spinal axons during the first 4 weeks posttransection (before behavioral recovery had occurred). Thirtyeight of 55 axons and neurites (69\%) emanating from 33 GIs terminated in the proper projection (Table 1). Eleven GIs sent out a total of 14 initially misoriented neurites originating from anomalous locations (Fig. 2D). Eleven of these 14 (79\%) attained a trajectory rostral and contralateral to the cell body. A weekly analysis revealed a reversible increase in the number of $1^{\circ}$ and $2^{\circ}$ dendrites at 2 weeks (Fig. 4), but no profusion of randomly oriented long neurites was observed. More than $90 \%$ of the axons and neurites from RAs and DCs also projected correctly during this same time period (Tables 2,3 ), consistent with the findings from GIs. These data show that the orientations of regenerating fibers early after axotomy were not substantially different from those at times after which behavioral recovery had occurred.

\section{Projections of cells located between two scars}

Regenerating lamprey spinal axons stop growing a short distance beyond the scar (Yin and Selzer, 1983). Therefore, a possible explanation for directional specificity is a tropic effect of the glial scar or some other component of the wound. If this is the predominent determinant in guiding fiber growth, then a cell positioncd between 2 scars should send out neurites equally in the rostral and caudal directions. Ten of 12 axons and long neurites $(83 \%)$ from 10 GIs located in an island formed by 2 transections had correct projection patterns (Table 1). Cells po- sitioned closer to the more rostral scar did not show a greater proportion of correctly oriented fibers than GIs positioned closer to the more caudal scar. Three GIs located closer to the more caudal scar sent out 4 initially misoriented neurites, of which 3 projected correctly (Fig. $5 B$ ). Seventeen of 18 axons and neurites (94\%) from DCs lucaled within an island also achieved their proper pathways, rostral and ipsilateral to the cell body (Table 3).

\section{Effect of eliminating potential distant synaptic targets}

In all 5 animals with rostral-caudal reversal of a $1 \mathrm{~cm}$ length of spinal cord, the reversed tissue did not survive. However, the spinal cord rostral and caudal to this region remained alive. The ends of these spinal cord sections were physically unattached. All 5 GIs injected in the caudal spinal cord section contained a single correctly oriented fiber, including 2 cells with neurites of anomalous origin (Fig. 5A). All axons and neurites of RAs ( 8 of 8 ) in the rostral section and of DCs (6 of 6) in the caudal section also projected in a pattern identical to that of their control counterparts. Thus, correct orientation was maintained despite the separation from distant synaptic targets located within the normal range of axon regeneration.

\section{Distances of growth of initially misoriented neurites}

If regeneration of lamprey spinal axons is guided by local factors that favor a specific direction, then fibers extending in the correct path should grow longer than those channeled in a wrong path. The 23 GIs that gave rise to 28 neurites of anomalous origin were evenly distributed with regard to recovery time and the distance of cell bodies to the scar. The mean distance of growth for the 23 correctly oriented neurites $(4317 \pm 584 \mu \mathrm{m}$; SEM) was more than double that for the 5 incorrectly oriented neurites $(2125 \pm 797 \mu \mathrm{m} ; p<0.05$; Fig. $6 B)$. Four GIs sent out both correctly and incorrectly oriented neurites. In 3 of these the

Table 2. Reticulospinal axon projection patterns

\begin{tabular}{|c|c|c|c|c|c|}
\hline Experiment & $\begin{array}{l}\text { No. of } \\
\text { axons }\end{array}$ & $\begin{array}{l}\text { Correct projections } \\
\text { of total no. of axons } \\
\text { or neurites }(\%)^{a}\end{array}$ & $\begin{array}{l}\text { No. of axons } \\
\text { that branch } \\
\text { and/or grow } \\
\text { beyond scar }\end{array}$ & $\begin{array}{l}\text { Correct projections } \\
\text { of total no. of } \\
\text { axons or ncurites } \\
\text { that branch and/or } \\
\text { grow beyond scar } \\
(\%)\end{array}$ & $\begin{array}{l}\text { No. of axons } \\
\text { with at least } \\
\text { one correct } \\
\text { projection }(\%)\end{array}$ \\
\hline Single transection recovery $>45 \mathrm{~d}$ & 92 & $189 / 208(91)$ & 46 & $149 / 162(92)$ & $83 / 92(90)$ \\
\hline Single transection recovery $<30 \mathrm{~d}$ & 27 & $34 / 39 \quad(87)$ & 5 & $12 / 17 \quad(71)$ & $27 / 27 \quad(100)$ \\
\hline Totals & 182 & $301 / 332(91)$ & 77 & $206 / 227(91)$ & $168 / 182(92)$ \\
\hline
\end{tabular}

${ }^{a}$ Correct projection defined as caudal and ipsilateral to parent axon. 

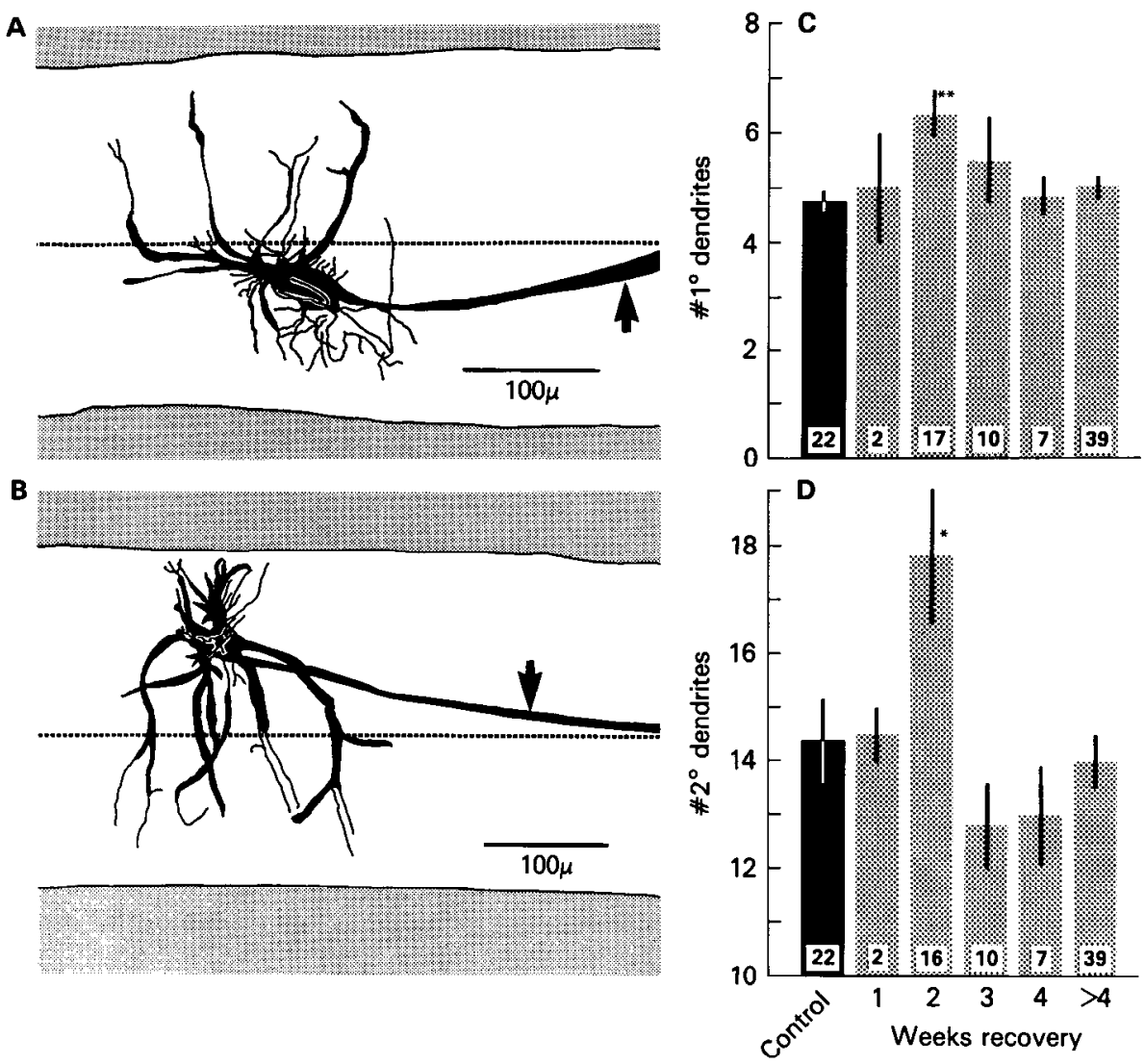

Figure 4. The number of $1^{\circ}$ and $2^{\circ}$ dendrites in GIs increases at 2 weeks' recovery time. $A, B$, GIs at 14 and $15 \mathrm{~d}$, respectively, after transection. (Compare with controls in GIs in Fig. $1, C, D$.) The original axon (arrow) is present in both cells. $C, D$, Time course of the increase in $1^{\circ}$ and $2^{\circ}$ dendrites. ${ }^{*} p<0.05,{ }^{* *} p<0.01$; Student's two-tailed $t$ test.

correctly projecting neurites grew further than the misdirected ones (Fig. $6 A$ ). These data show that the distances of growth of regenerating GI neurites are greater when the fibers project in the normal direction.

\section{Discussion}

The present studies demonstrate that regenerating spinal axons in 4-5-year-old larval lampreys exhibit a remarkable tendency to grow selectively in their normal direction. Overall, more than $86 \%$ of 562 HRP-stained axons and axon-like neurites regenerated in the correct direction. Factors involved in determining the direction of axonal growth during development are now being revealed in other nervous systems. Axonal guidance in the invertebrate peripheral nervous system appears to rely partly upon interactions between fibers of peripheral "pioneer" neurons and an adhesive hierarchy provided by epithelial and neuronal surfaces (Berlot and Goodman, 1984). Growth cones of these cells contact, via gap junctions, the "stepping-stone" neurons they encounter along their centripetal path into the CNS (Bate, 1976). Axons within the invertebrate CNS form fascicles by means of a process in which they selectively recognize appropriate neighbors (Raper et al., 1983). Possible factors involved in the formation of precise projection patterns in the more complex vertebrate nervous system are thought to include mechanical routing (Weiss, 1934) and the recognition of chemical signals (Sperry, 1963). In vitro studies have demonstrated

Table 3. Dorsal cell projection patterns

\begin{tabular}{|c|c|c|c|c|c|}
\hline Experiment & $\begin{array}{l}\text { No. of } \\
\text { cells }\end{array}$ & $\begin{array}{l}\text { Correct projections } \\
\text { of total no. of axons } \\
\text { or neurites }(\%)^{\alpha}\end{array}$ & $\begin{array}{l}\text { No. of cells } \\
\text { with axons } \\
\text { that branch } \\
\text { and/or grow } \\
\text { beyond scar }\end{array}$ & $\begin{array}{l}\text { Correct projections } \\
\text { of total no. of } \\
\text { axons or neurites } \\
\text { that branch and/or } \\
\text { grow beyond scar } \\
\text { (\%) }\end{array}$ & $\begin{array}{l}\text { No. of cells } \\
\text { with at least } \\
\text { one correct } \\
\text { projection (\%) }\end{array}$ \\
\hline Single transection recovery $>45 \mathrm{~d}$ & 35 & $35 / 38(92)$ & 9 & $9 / 12(75)$ & $33 / 35(94)$ \\
\hline Single transection recovery $<30 \mathrm{~d}$ & 15 & $19 / 20(95)$ & 7 & $11 / 12(92)$ & $14 / 15(93)$ \\
\hline Totals & 73 & $79 / 84(94)$ & 20 & $27 / 31(87)$ & $69 / 73(95)$ \\
\hline
\end{tabular}

${ }^{a}$ Correct projection defined as rostral and ipsilateral to cell body. 


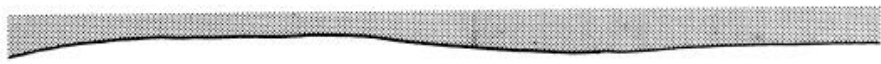

A

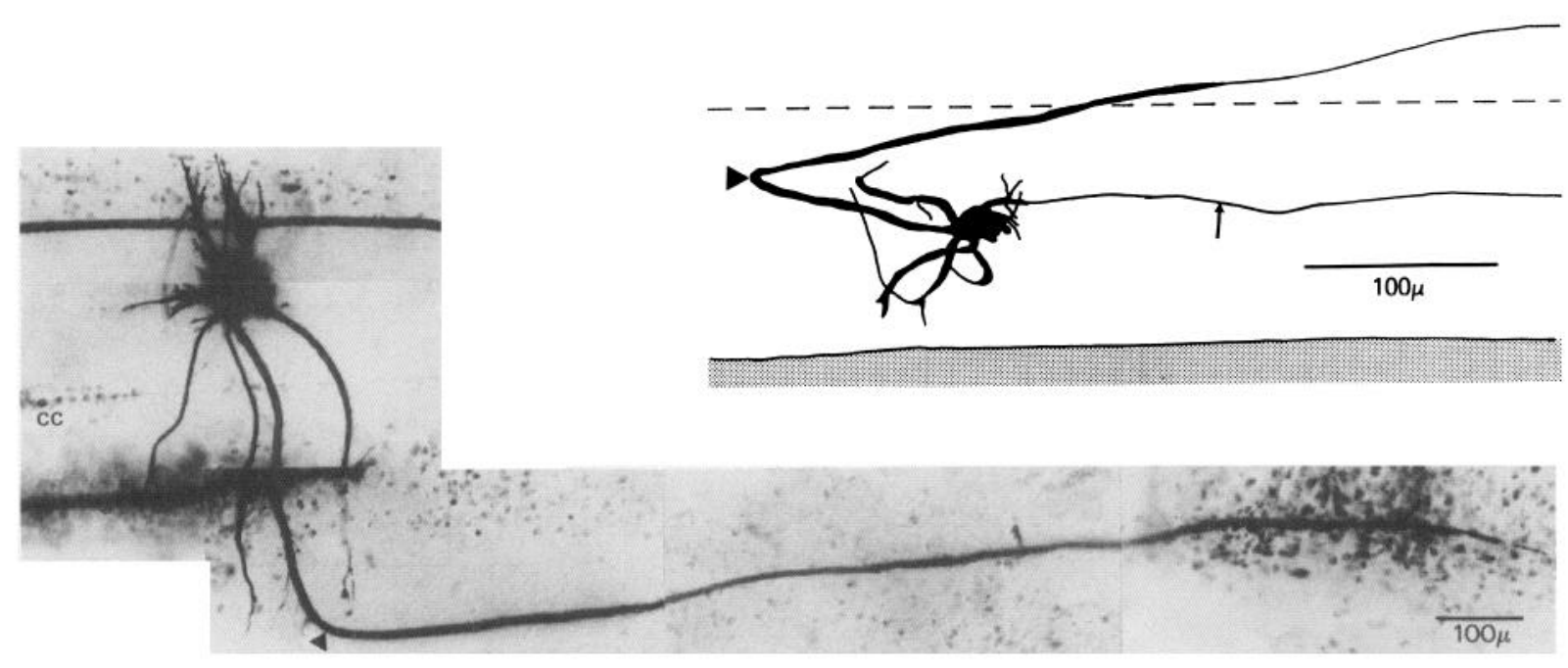

Figure 5. Lack of effect of missing region of spinal cord and of scar location on the direction of regeneration of GI neurites. A, A GI located 1 $\mathrm{mm}$ below a missing spinal cord section at $84 \mathrm{~d}$ of recovery. Despite the absence of potential remote synaptic targets, a neurite loops to attain a correct (contralateral and rostral) projection (arrowhead). $c c$, Central canal. B, A GI located between scars formed by a double simultaneous transection performed $60 \mathrm{~d}$ previously. Although this cell is closer to the caudal scar, 2 neurites (small arrow and arrowhead) grow rostrally, indicating that the scar tissue did not determine the direction of neurite growth.

that an exogenous electrical field (of a magnitude similar to those created by endogenous currents during neuronal and muscle activity) can influence the direction of growth of vertebrate neurites (Jaffe and Poo, 1979; Patel et al., 1985). It is not known if these mechanisms are mutually exclusive and what molecules provide the signals. Analogous with these hypotheses, our results suggest that directional specificity in the regeneration of lamprey spinal axons is determined by cues in the local environment of the growing tip. The projection patterns are imposed early in the recovery period, before the processes achieve the appearance of axon-like neurites. The cues are neither limited to mechanical guidance through pathways formed by degenerating fibers nor to a tropic influence of remote structures such as the scar or distant synaptic targets. Furthermore, assuming that similar determinants are involved in the initial development of the lamprey CNS, the signals for axonal guidance are maintained for years after the axon tracts have been formed.

\section{Axon projections in behaviorally recovered animals}

Directional specificity occurs in the regeneration of both ascending (GIs and DCs) and descending (RAs) pathways. The hypothesis that axons grow in an already established direction does not explain the results in GIs with neurites of anomalous origin. These growing fibers are initially misoriented and must change their trajectory to achieve the proper projection (Figs. $2 C, 6 A$ ). Also, the findings from RAs and DCs cannot be explained by dieback of damaged fibers without subsequent outgrowth. This is because more than $90 \%$ of axons and neurites from RAs and DCs that branched or grew beyond the scar (and therefore added new lengths of membrane) extended in the correct orientation (Fig. 3). In addition, it has been reported that the average distance of retraction of RAs in the first week postaxotomy is $1750 \mu \mathrm{M}$ (Roederer et al., 1983). Our own unpublished observations suggest that dieback is of even greater magnitude by 2 weeks. Nearly all the RAs of behaviorally recovered animals in the present study had grown to within $1500 \mu \mathrm{M}$ from the center of the scar, beyond the expected distances of dieback.

\section{Projections formed before behavioral recovery}

The precision with which lamprey spinal axons grow is seen early in regeneration. The possible explanation that the fibers were already pointed in the right direction is contradicted by the finding that 11 of $14 \mathrm{GI}$ neurites that originated anomalously looped to attain a correct orientation (Fig. 2D). The increase in the number of $1^{\circ}$ and $2^{\circ}$ dendrites 2 weeks after spinal transection is distinctly different from the profuse neuritic sprouting caused by proximal axotomy of reticulospinal axons (Hall and Cohen, 1983). In the latter, the neurites increase in number and length for many weeks and have the appearance of axons. In GIs, the increase in dendrites is quickly reversed and only $0-3$ axon-like neurites are formed. The significance of the transient increase in the number of $1^{\circ}$ and $2^{\circ}$ dendrites is not known. A process of selective retraction may occur while cell processes are short, thereby selecting correctly oriented neurites while they are still part of the dendritic tree. On the other hand, the change in dendritic number may be unrelated to axonal regeneration but reflect the synaptic reorganization occurring after axotomy and partial denervation (Yin et al., 1984b). In any case, directional specificity is clearly not the result of random sprouting of long axon-like neurites with subsequent removal of incorrectly oriented ones.

\section{Projections formed long after double simultaneous transections}

We considered the possibility that release of a tropic factor at the lesion site was the predominant influence in axonal guidance. If this were true, cells located within an island formed by 2 transections would be faced with equal attractive forces above and below, and the growth should be random. More than $95 \%$ of stained neurites of GIs and DCs located within islands regenerated in the correct direction. Even when the cells were located closer to the caudal scar, 9 of 12 axons and neurites from 11 GIs and DCs grew along their original rostralward paths (Fig. 5B). Thus, growth towards an increasing gradient of a tropic 
Figure 6. GI neurites positioned in correct pathways grow further than incorrectly projecting neurites. $A, \mathrm{~A}$ GI $64 \mathrm{~d}$ after single transection. The neurite projecting ipsilaterally and rostralward (small arrow) terminates about $1 \mathrm{~mm}$ from the cell. Another neurite arising from a contralateral dendrite sends 2 branches in the correct projection. These fibers grow beyond the scar [located wherc the central canal $(c c)$ widens]. A third fiber (probably the original axon) gives rise to several branches. These branches also remain correctly positioned and grow beyond the scar. Because they may arise from the original axon, these branches are not included in the bar graph in $B$. $c$, Central canal. $B$, In 28 GIs, the distance of growth of properly oriented neurites is more than double that of incorrectly oriented neurites $(p<0.05)$.
A
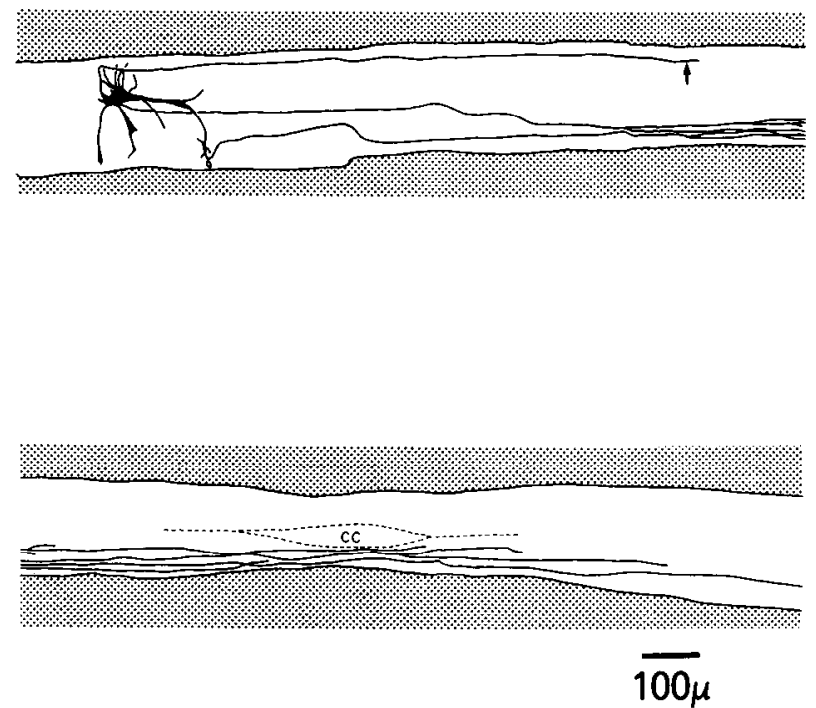

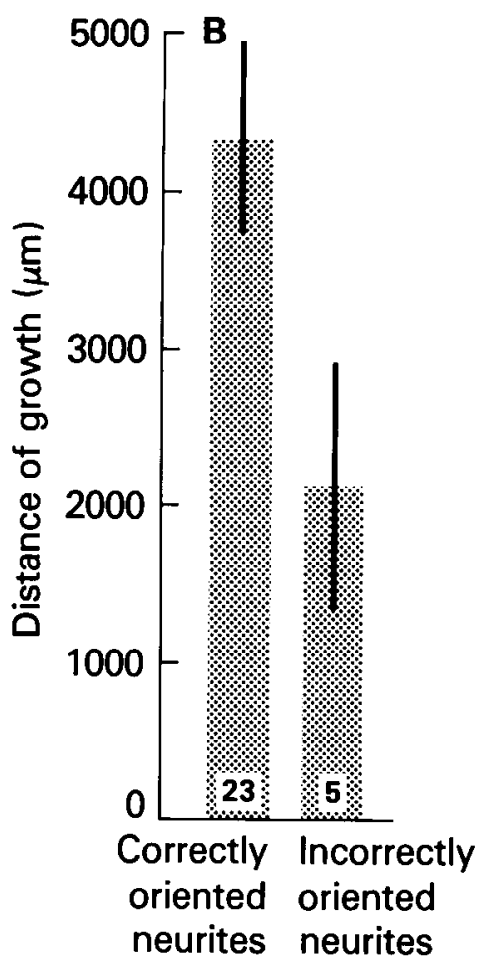

factor released at the transection site cannot account for the ability of regenerating fibers to attain proper projection pattcrns.

Regenerating neurites might follow pathways formed by distal segments of transected lamprey axons, since they do undergo Wallerian degeneration (Selzer, 1978; Tang and Selzer, 1979). For GIs and DCs located within an island formed by a double transection, Wallerian degeneration of rostrally and caudally projecting axons opens up equal amounts of space in all directions (rostral, caudal, ipsilateral, and contralateral). If the direction of axon growth had been determined primarily by the availability of opened spaces, the projection patterns of regenerating neurites from such GIs and DCs should have been random. Yet, they clearly were not (Tables 1,2$)$. Following a single transection, axons could grow either toward their own degenerating distal segments or in the reverse direction, towards the degenerating distal segments of oppositely projecting cells. However, the majority of spinal axons and neurites in ammocoetes that recovered more than 6 weeks after a single transection was correctly oriented (Tables 1-3). These data suggest that the mechanical routing hypothesized to guide axons in developing vertebrate spinal cord (Singer et al., 1979) and optic nerve (Silver and Sidman, 1980) pathways is most likely not the major determinant in guiding lamprey axonal regeneration.

\section{Projections after removal of distant synaptic targets}

Reversals of short segments of spinal cord along the rostralcaudal axis were attempted in order to be able to distinguish between the possible roles of local and remote factors in guiding axon regeneration. These spinal cord pieces did not survive, presumably because of interruption of the blood supply. However, the effect of this maneuver was to eliminate the potential synaptic targets within the range of regeneration of rostrally and caudally projecting neurons of segments below and above the necrotic island, respectively. These axons still attained proper projection patterns within their stump; this included 8 of 8 neurites of GIs and DCs in which new growth undoubtedly occurred (Fig. 5A; Tables 1, 3). Therefore, distant synaptic targets do not appear to be necessary for regenerating spinal axons to grow along proper paths. Similar conclusions were recorded in expcriments on the motor innervation of the developing chick limb bud (Lewis et al., 1981; Tosney and Landmesser, 1984). Normally, lamprey spinal axons form synapses en passant. Many of these synapses contain gap junctions (Rovainen, 1979). The multiple synaptic targets might act as stepping-stones in axonal guidance analogous to the relationship betwcen landmark cells and pioneer neurons in the invertebrate limb (Bate, 1976).

As was mentioned previously, the whole-mount technique does not allow one to reliably identify the individual tracts into which an axon grows. This requires serial sectioning. Serial light microscopy (Selzer, 1978) revealed that $71 \%$ of 28 branches from 18 axotomized RAs regenerated along their original tracts. Our observations on the much larger number of axons in wholemount preparations, although not listed quantitatively, also suggested that regenerating lamprey axons grow into appropriate tracts. Axons of DCs were nearly always positioned medially and most axons and neurites of GIs projected lateral to the medial columns.

Exogenously applied electrical fields enhanced RA regeneration in the lamprey spinal cord (Borgens et al., 1981). Neurites of vertebrate neurons in vitro also grow toward a cathode (Jaffe and Poo, 1979). Since transected lamprey axons generate electrical currents at their cut ends (Borgens et al., 1980) it might be supposed that electrical fields play a role in determining the direction of axonal growth. However, the electrically induced enhancement of lamprey axonal regeneration most likely resulted from a reduction in the amount of dieback before the regenerative process began (Roederer et al., 1983). Also, the magnitude of endogenous currents located at the transected spinal cord decreased dramatically in the first week of recovery (Borgens et al., 1980). Thus, the relation of electric fields to the directional specificity in the regeneration of lamprey spinal axons is not clear.

We conclude that (1) regenerating lamprey spinal axons grow along their original projection paths; (2) this directional specificity does not result from random long neurite outgrowth and subsequent selective retraction, a tropic effect of the scar tissue 
or distant synaptic targets, or mechanical routing through channels formed by degenerating fibers; (3) correctly oriented neurites will grow further than incorrectly oriented ones; and (4) the factors responsible for axonal guidance appear to be maintained years after development of the axon tract is completed. A possible explanation is that lamprey neurons retain their ability to respond to as yet unidentified biochemical cues in the local environment and are further aided by the stepping-stone effect of en passant synapse formation.

It is not clear if behavioral recovery following spinal transection in lower vertebrates depends upon the regeneration of synapses that are specific for the original pattern of neuronal interconnections. If this is the case, then regenerating axons would first have to grow in their original directions before they could encounter their original synaptic targets. In the larval lamprey spinal cord, in which functional synaptic connections are formed during regeneration (Mackler and Selzer, 1985a), 94\% of all cells studied (319 of 341) sent at least one fiber in the correct direction (Tables 1-3). Selectivity of synapse formation during regeneration is an attractive hypothesis for which there is as yet only preliminary evidence (Mackler and Selzer, 1985b). If true, it would indicate the persistence, long after development, not only of axonal guidance factors but of those determinants involved in selective recognition of synaptic targets.

\section{References}

Bate, C. M. (1976) Pioneer neurones in an insect embryo. Nature 260: 54-55.

Berlot, J., and C. S. Goodman (1984) Guidance of peripheral pioneer neurons in the grasshopper: Adhesive hierarchy of epithelial and neuronal surfaces. Science 223: 493-495.

Borgens, R. B., L. F. Jaffe, and M. J. Cohen (1980) Large and persistent electrical currents enter the transected lamprey spinal cord. Proc. Natl. Acad. Sci. USA 77: 1209-1213.

Borgens, R. B., E. Roederer, and M. J. Cohen (1981) Enhanced spinal cord regeneration in lamprey by applied electrical fields. Science 213: 611-617.

Hall, G. F., and M. J. Cohen (1983) Extensive dendritic sprouting induced by close axotomy of central neurons in the lamprey. Science 222: 518-521.

Hanker, J. S., P. E. Yates, C. B. Metz, and A. Rustioni (1977) A new specific, sensitive, and non-carcinogenic reagent for the demonstration of horseradish peroxidase. Histochem. J. 9: 789-792.

Hibbard, E. (1963) Regeneration in the severed spinal cord of chordate larvae of Petromyzon marinus. Exp. Neurol. 7: 175-185.

Hibbard, E. (1965) Orientation and directed growth of Mauthner's cell axons from duplicated vestibular nerve roots. Exp. Neurol. 13: 289-301.

Jacobson, C.-O. (1976) Motor nuclei, cranial nerve roots, and fibre pattern in the medulla oblongata after reversal experiments on the neural plate of Axolott larvae. Zoontology 4: 87-100.

Jaffe, L. F., and M.-M. Poo (1979) Neurites grow faster towards the cathode than the anode in a steady field. J. Exp. Zool. 209: 115-128.

Lance-Jones, C., and L. Landmesser (1981) Pathway selection by embryonic chick motoneurones in an experimentally altered environment. Proc. R. Soc. Lond. [Biol.] 214: 19-52.

Lewis, J., A. Chevallier, M. Kieny, and L. Wolpert (1981) Muscle nerves do not develop in chick wing devoid of muscle. J. Embryol. Exp. Morphol. 64: 211-232.

Mackler, S. A., and M. E. Selzer (1985a) Regeneration of functional synapses between individual recognizable neurons in the lamprey spinal cord. Science 229: 774-776.
Mackler, S. A., and M. E. Selzer (1985b) Elements of specificity in synaptic regeneration between lamprey spinal neurons. Soc. Neurosci. Abstr. 11: 973.

Martin, R. J., and D. Bowsher (1977) An electrophysiological investigation of the projection of the intramedullary primary afferent cells of the lamprey ammocoete. Neurosci. Lett. 5: 39-43.

Patel, N. B., Z.-P. Xie, S. H. Young, and M.-M. Poo (1985) Response of nerve growth cone to focal electric currents. J. Neurosci. Res. 13: 245-256.

Raper, T. A., M. T. Bastiani, and C. S. Goodman (1983) Guidance of neuronal growth cones: Selective fasciculation in the grasshopper embryo. Cold Spring Harbor Symp. Quant. Biol. 48: 587-598.

Roederer, E., N. II. Goldberg, and M. T. Cohen (1983) Modification of retrograde degeneration in transected spinal axons of the lamprey by applied DC current. J. Neurosci. 3: 153-160.

Rovainen, C. M. (1967a) Physiological and anatomical studies on large neurons of central nervous system of the sea lamprey (Petromyzon marinus). I. Muller and Mauthner cells. J. Neurophysiol. 30: 10001023.

Rovainen, C. M. (1967b) Physiological and anatomical studies on large neurons of central nervous system of the sea lamprey (Petromyzon marinus). II. Dorsal cells and giant interneurones. J. Neurophysiol. 30: 1024-1042.

Rovainen, C. M. (1976) Regeneration of Muller and Mauthner axons after spinal transection in larval lampreys. J. Comp. Neurol. 168: 545-554.

Rovainen, C. M. (1979) Neurobiology of lampreys. Physiol. Rev. (Lond.) 59: 1007-1077.

Selzer, M. E. (1978) Mechanisms of functional recovery and regeneration after spinal cord transection in larval sea lampreys. J. Physiol. (Lond.) 277: 395-408.

Selzer, M. E. (1979) Variability in maps of identified neurons in the sea lamprey spinal cord examined by a wholemount technique. Brain Res. 163: 181-193.

Silver, J., and R. L. Sidman (1980) A mechanism for the guidance and topographic patterning of retinal ganglion cell axons. J. Comp. Neurol. 189: 101-111.

Singer, M., R. H. Nordlander, and M. Egar (1979) Axonal guidance during embryogenesis and regeneration in the spinal cord of the newt: The blueprint hypothesis of neuronal pathway patterning. J. Comp. Neurol. 185: 1-22.

Sperry, R. W. (1963) Chemoaffinity in the orderly growth of nerve fiber patterns and connections. Proc. Natl. Acad. Sci. USA 50: 703710.

Stefanelli, A. (1951) The Mauthnerian apparatus in the Ichthyopsida. Q. Rev. Biol. 26: 17-34.

Tang, D., and M. E. Selzer (1979) Projections of lamprey spinal neurons determined by the retrograde axonal transport of horseradish peroxidase. J. Comp. Neurol. 188: 629-645.

Tosney, K. W., and L. Landmesser (1984) Pattern and specificity of axonal outgrowth following varying degrees of chick limb bud ablation. J. Neurosci. 4: 2518-2527.

Weiss, $P$. (1934) In vitro experiments on the factors determining the course of the outgrowth nerve fiber. J. Exp. Zool. 68: 393-448.

Wood, M. R., and M. J. Cohen (1981) Synaptic regeneration and glial reactions in the transected spinal cord of the lamprey. J. Neurocytol. 10: 57-79.

Yin, H. S., and M. E. Selzer (1983) Axonal regeneration in the lamprey spinal cord. J. Neurosci. 3: 1135-1144.

Yin, H. S., S. A. Mackler, and M. E. Selzer (1984a) Directional specificity in the regeneration of lamprey spinal axons. Science 224: 894896.

Yin, H. S., S. A. Mackler, and M. E. Selzer (1984b) Effects of axotomy on lamprey interneurons. Soc. Neurosci. Abstr. 10: 1025. 